\title{
Mass trapping with MosquiTRAPs does not reduce Aedes aegypti abundance
}

\author{
Carolin Marlen Degener ${ }^{1,2} /^{+}$, Tatiana Mingote Ferreira de Ázara ${ }^{1,3}$, Rosemary Aparecida Roque ${ }^{4}$, \\ Susanne Rösner ${ }^{5}$, Eliseu Soares Oliveira Rocha ${ }^{6}$, Erna Geessien Kroon ${ }^{6}$, Cláudia Torres Codeço ${ }^{2}$, \\ Aline Araújo Nobre ${ }^{2}$, Jörg Johannes Ohly ${ }^{7}$, Martin Geier $^{8}$, Álvaro Eduardo Eiras ${ }^{1}$
}

\begin{abstract}
'Laboratório de Ecologia Química de Vetores, Departamento de Parasitologia ${ }^{6}$ Laboratório de Vírus, Universidade Federal de Minas Gerais, Belo Horizonte, MG, Brasil ²Programa de Computação Científica, Fundação Oswaldo Cruz, Rio de Janeiro, RJ, Brasil

${ }^{3}$ Secretaria de Estado de Saúde de Minas Gerais, Belo Horizonte, MG, Brasil ${ }^{4}$ Laboratório de Entomologia Aplicada, Universidade Nilton Lins, Manaus, AM, Brasil ${ }^{5}$ Abteilung Wissenschaft und Diagnostik, Forel Klinik, Ellikon an der Thur, Switzerland ${ }^{7}$ Centro de Estudos Superiores do Trópico Úmido, Universidade do Estado do Amazonas, Manaus, AM, Brasil ${ }^{8}$ Biogents AG, Regensburg, Germany
\end{abstract}

The objective of this study was to evaluate the effectiveness of Aedes aegypti mass trapping using the sticky trap MosquiTRAP (MQT) by performing a cluster randomised controlled trial in Manaus, state of Amazonas, Brazil. After an initial questionnaire and baseline monitoring of adult Ae. aegypti abundance with BG-Sentinel (BGS) traps in six clusters, three clusters were randomly assigned to the intervention arm where each participating household received three MQTs for mass trapping during 17 months. The remaining three clusters (control arm) did not receive traps. The effect of mass trapping on adult Ae. aegypti abundance was monitored fortnightly with BGS traps. During the last two months of the study, a serological survey was conducted. After the study, a second questionnaire was applied in the intervention arm. Entomological monitoring indicated that MQT mass trapping did not reduce adult Ae. aegypti abundance. The serological survey indicated that recent dengue infections were equally frequent in the intervention and the control arm. Most participants responded positively to questions concerning user satisfaction. According to the results, there is no evidence that mass trapping with MQTs can be used as a part of dengue control programs. The use of this sticky trap is only recommendable for dengue vector monitoring.

Key words: MosquiTRAP - mosquito traps - dengue control - mass trapping - Aedes aegypti

Dengue is currently the most important arboviral disease that affects humans. Some factors that are associated with the increasing disease incidence and severity are globalisation, unplanned urbanisation and the absence of efficient vector control techniques (Gubler 2011). The development and implementation of new efficient vector control strategies represent an important component in an attempt to revert the tendency of increasing dengue incidence (Maciel-de-Freitas et al. 2012).

The control of Aedes aegypti (L.), the main vector of the disease is challenging because the mosquito is adapted to the urban environment with its high density of breeding sites and human hosts. A variety of alternative Ae. aegypti control strategies are being developed, including biological and genetic approaches (Kay \& Vu 2005, Kroeger et al. 2006, Kittayapong et al. 2008, Hoffmann et al. 2011, Lacroix et al. 2012, Nam et al. 2012, Lenhart et al. 2013).

Ovitraps were developed in the 1960s (Fay \& Eliason 1966) and have been used since then for dengue vector monitoring. In the 1970s, they were used for the first time

doi: 10.1590/0074-02760140374

Financial support: The World Bank, UEA, CAPES, CNPq [PRONEXDengue (550131/2008-8)], INCT-Dengue

+ Corresponding author: carolindegener@hotmail.de

Received 10 October 2014

Accepted 20 March 2015 as a component in an Ae. aegypti control program (Chan 1972). Almost three decades later, the ovitrap was adapted to be lethal for ovipositing females, by impregnating the oviposition strip with an insecticide (Zeichner \& Perich 1999). This modified trap of the type "lure-and-kill" was named lethal ovitrap (LO). Since the last decade, mass application of LOs has been evaluated for the control of dengue vectors (Perich et al. 2003, Sithiprasasna et al. 2003, Ocampo et al. 2009, Rapley et al. 2009). Most of these studies had positive or partly positive results.

Sticky ovitraps, another lethal adaptation of the ovitrap, contain a sticky surface and therefore permit the collection of adult gravid mosquitoes (Ritchie et al. 2003, Fávaro et al. 2006, Mackay et al. 2013). The Centers for Disease Control and Prevention autocidal gravid ovitrap (CDC-AGO trap) was recently shown to be effective to control Ae. aegypti field populations in Puerto Rico (Barrera et al. 2014a, b).

In a previous study, we reported that mass trapping with BG-Sentine $\mathrm{l}^{\mathbb{B}}$ (BGS) traps, a suction trap for adult mosquitoes, significantly reduced the abundance of adult Ae. aegypti females in Manaus, state of Amazonas, Brazil, during the first rainy season of the study period (Degener et al. 2014). Parallel to the BGS trial, we evaluated the MosquiTRAP ${ }^{\circledR}$ (MQT) for adult dengue vector control. The MQT mass trapping experiment is described in the present paper.

The sticky MQT does not require electricity and attracts gravid mosquitoes through visual (black colour) and olfactory (synthetic oviposition attractant) cues (Fá- 
varo et al. 2006, Eiras \& Resende 2009). MQT-entering mosquitoes get trapped on a sticky card, which can easily be removed for species identification during trap inspections (Eiras \& Resende 2009). Trapped mosquitoes can also be used for virus identification (Vilela et al. 2010). The MI-Dengue, a real-time, citywide mosquito trapping system for weekly monitoring of gravid Ae. aegypti, uses the MQT as the main tool (Eiras \& Resende 2009). Traps are spaced in a grid-like manner at $200 \mathrm{~m}$ intervals and vector density data are automatically available for control personnel who respond by applying source reduction or adulticide activities in areas of high mosquito abundance. The MI-Dengue mosquito surveillance and control system was evaluated as being cost-effective in Brazil (Pepin et al. 2013).

The MQT has been used over a decade for Ae. aegypti monitoring in several Brazilian cities. In this study, we describe the first Ae. aegypti mass trapping experiment with this trap. The aim is to reduce the dengue vector population and dengue transmission by trapping adult mosquitoes.

\section{PATIENTS, MATERIALS AND METHODS}

Study area - The study was conducted in the Cidade Nova neighbourhood of Manaus ( $3^{\circ} 07^{\prime} \mathrm{S} 59^{\circ} 57^{\prime} \mathrm{W}$ ) (Fig. 1A, B). Manaus and Cidade Nova had estimated populations of 1,802,014 and 121,135 in 2010 (IBGE 2010). The houses of the mainly residential neighbourhood are made of wood or brick, usually with verandas and/or backyards. The majority of them (97\%) had piped water and most streets were paved. Six clusters, areas consisting of 104-150 houses (mean $=129$ houses, total: 775 houses) were selected (Fig. 1C, Table I). Clusters had a minimum distance of $250 \mathrm{~m}$ between each other in order to avoid spill-over effects.

Entomological monitoring - Monitoring of adult Ae. aegypti mosquitoes was conducted fortnightly using four BGS traps (Biogents AG, Germany) per cluster. The BGS traps (12 in the intervention and 12 in the control arm) were installed once per fortnight for a period of $24 \mathrm{~h}$ in the peridomestic area of four non-neighbouring houses within 30 centrally located houses of each cluster, as previously described (Degener et al. 2014). After two months of baseline monitoring, clusters with similar female Ae. aegypti catches were paired and, of each pair, one cluster was randomly chosen (flipping of a coin) to receive MQT mass trapping treatment. Mosquito identification and determination of parity status was performed as previously described (Degener et al. 2014).

Questionnaires - An informative folder about the planned study was distributed in all households three months prior to the mass trapping intervention. Households were visited by trained fieldworkers for the application of a questionnaire in form of a direct interview with questions about demographics, dengue knowledge, practice and experience.

A second questionnaire was applied in participating households of the intervention arm after trap removal. It included questions about perceived trap effectiveness, problems, improvements, user satisfaction and indicators of the subjective value of the trap.

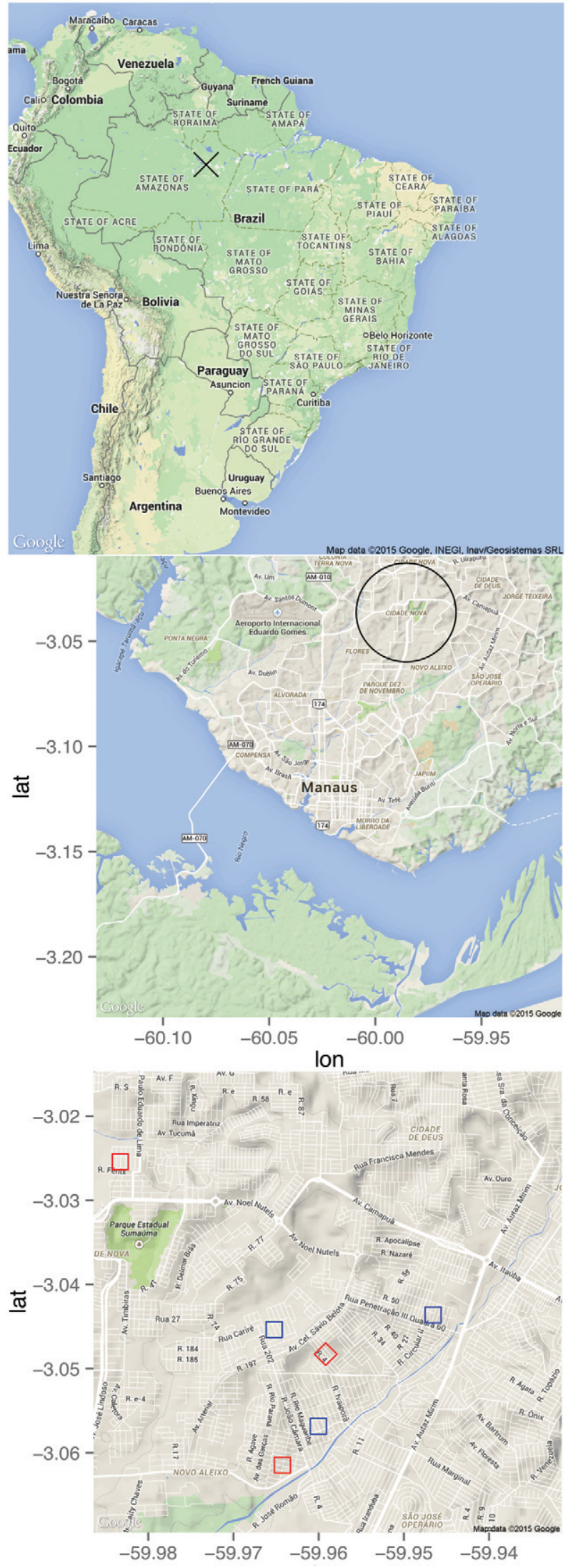

Fig. 1: maps of the study area. A: Brazil and the localisation of Manaus, state of Amazonas (black "X"); B: Manaus and the localisation of Cidade Nova (black circle); C: Cidade Nova with the localisation of three mass trapping (blue) and three control areas (red). 
TABLE I

Numbers of households in each cluster by category (intervention and control arm)

\begin{tabular}{lcc}
\hline Pair & $\begin{array}{c}\text { Intervention } \\
\text { (n) }\end{array}$ & $\begin{array}{c}\text { Control } \\
\text { (n) }\end{array}$ \\
\hline 1 & 117 & 104 \\
2 & 149 & 150 \\
3 & 137 & 118 \\
\hline Total & 403 & 372 \\
\hline
\end{tabular}

MQT mass trapping - MQTs (Ecovec Ltd, Brazil) for mass trapping were distributed after baseline monitoring in all houses of the intervention arm (three clusters), whose inhabitants agreed to participate through written informed consent (206 from 403 houses; 51.1\%). Three MQTs were installed in each household, preferentially in the peridomestic area (covered yard areas or verandas), protected from direct sunlight and strong rain, where possible at ground level (alternatively at a maximum height of $1.5 \mathrm{~m}$ above the ground). Traps in the same household were positioned at least $5 \mathrm{~m}$ apart from each other, preferentially in different environments (example for 3 positions: veranda, yard, laundry area).

During fortnightly trap inspections, mosquitoes from all three traps were identified, sexed and counted with the help of a hand-held magnifying glass. Obtained data (sum of 3 traps) were registered in a cell phone program and immediately sent to an online database of Ecovec Ltd. The sticky cards were replaced after eight-10 weeks or earlier when necessary. The oviposition attractants (AtrAedes ${ }^{\circledR}$, Ecovec Ltd), which were fixed on the sticky cards, were replaced every six weeks. The water in the bottom half of every MQT $(300 \mathrm{~mL})$ was replaced during every trap inspection and one drop of Bacillus thuringiensis var. israelensis (Bti) (BT-horus $\mathrm{SC}^{\circledR}$, Brazil) was added to avoid development of mosquito larvae. The MQTs remained installed for 17 months, from February 2009-June 2010. Control clusters did not receive dummy traps.

Serological survey - Blood samples (whole blood on sterilised filter paper) were collected during the last two months of the study. Dengue virus (DENV) IgM-seropositivity of residents was investigated through an IgM ELISA as previously described (Degener et al. 2014). Samples were obtained from 340 residents, 191 from the intervention and 149 from the control arm. Participants of intervention and control clusters had a mean age [ \pm standard deviation (SD)] of $36.8 \pm 18.6$ and $31.3 \pm 20.1$ years, respectively.

Study design and outcome measures - A matched pair cluster randomised controlled trial (with 3 intervention and 3 control areas) was used to allocate intervention and control status of households. Baseline collection of entomological indicators (abundance of adult female Ae. aegypti in BGS traps) confirmed similar mosquito densities in intervention and control clusters. Participat- ing households in the intervention arm received three MQTs for mass trapping. We randomised clusters rather than households, to account for the possibility of clusterlevel effects of the intervention.

The primary outcome measure was the number of $A e$. aegypti females collected fortnightly in BGS monitoring traps. Secondary outcome measures were the parity rates of females captured with BGS traps, the frequency of DENV IgM seropositivity among cluster inhabitants and the results of the second household interview survey.

Statistical methods - The six time series of female Ae. aegypti collections were analysed using mixed effects model. We used first a generalised additive mixed models (GAMM) without covariates to describe the average trend of mosquito infestation in the mass trapping and in the control arm:

$$
\mathrm{Y}_{h i}=\alpha+\mathrm{f}_{T h}(i)+\mathrm{a}_{h}+\varepsilon_{h i}
$$

$\mathrm{Y}_{h i}$ is the $\log _{10}$ transformed mean catch rate of female Ae. aegypti for cluster $h(h=1, \ldots, 12)$ at calendar time (fortnight) $i(i=1, \ldots, 41)$; $\alpha$ is the intercept, $\mathrm{f}_{T h}(i)$ is the smooth nonlinear effect of calendar time $i$ in each $\operatorname{arm} T_{h}$ ( $T_{h}=0$ for control arm, $T_{h}=1$ for the treatment arm), $\mathrm{a}_{h}$ is the random intercept with the distribution $\mathrm{a}_{h} \sim \mathrm{N}\left(0, \tau^{2}\right)$. As the spread of the residual error $\varepsilon_{h i}$ varied per cluster, a heteroscedastic model was used with $\varepsilon_{h i} \sim \mathrm{N}\left(0, \sigma_{\mathrm{h}}^{2}\right)$.

Differences between treatment and control arm during baseline monitoring were tested by fitting linear mixed effect (LME) models including the fixed factor treatment and the random effect cluster.

$$
\mathrm{Y}_{h i}=\alpha+\beta T_{h}+\mathrm{a}_{h}+\varepsilon_{h i}
$$

$T_{h}$ is a dummy variable (treatment) indicating control $\left(T_{h}=0\right)$ or intervention $\left(T_{h}=1\right)$ status of clusters, $\beta$ is the fixed effect of mass trapping.

The effect of intervention throughout the whole study period was evaluated with the following GAMM:

$$
\mathrm{Y}_{h i}=\alpha+\beta_{1} \cdot T_{h}+\beta_{2} \cdot P_{h}+\beta_{3} \cdot T_{h} \cdot P_{h}+\mathrm{f}_{T h}(i)+\mathrm{a}_{h}+\varepsilon_{h i}
$$

$P_{h}$, the $\log _{10}$-transformed and centred mean number of female Ae. aegypti caught during baseline monitoring (Clogbaseline), was included in the model to account for the differences between clusters $h$ at baseline. $\beta$ 's are the fixed effects of the mass-trapping intervention $\left(\beta_{1}\right)$, the pretreatment mosquito density $\left(\beta_{2}\right)$ and their interaction $\left(\beta_{3}\right)$.

Since models (1) and (3) suggested that the effect of treatment varied with time, further GAMM was conducted considering each of the three different periods of the study separately: weeks 1-22 (1st rainy season), weeks 2342 (dry season) and weeks 43-73 (2nd rainy season).

Additionally, as the abundance of female Ae. aegypti in one of the intervention clusters was exceptionally high, a reduced dataset considering only two pairs of clusters was analysed, using the same above-mentioned models, however without inclusion of the random factor cluster and without the heteroscedastic residual error distribution $\left[\varepsilon_{h i} \sim \mathrm{N}\left(0, \sigma^{2}\right)\right]$. Thus, generalised additive models (GAM) were used instead of model (1) and (3) and a linear model was used instead of model (2). Mixed models were also adjusted, but as the estimated variance 
between clusters was close to zero, the inclusion of the random intercept was not justified. The fits of all models were evaluated through diagnostic plots.

Differences of binary outcomes of the first household interview survey between intervention and control were modelled using logistic mixed models (LMMs) with the dummy variable treatment $\left(T_{h}\right)$ as a fixed effect and cluster $(h)$ as random effect.

Parity during baseline and during each of the three intervention periods was compared using Fisher's exact test. This test was chosen, as during each period, extremely few nulliparous mosquitoes were collected.

The frequency of IgM-positivity was also evaluated using Fisher's exact test, as the frequency of seropositivity was extremely low.

All statistical analyses were performed using the statistical software R 2.12.1 (R Development Core Team 2010); GAMM, LME and LMM were implemented using the libraries mgcv (Wood 2006), nlme (Pinheiro et al. 2010) and lme4 (Bates et al. 2011), respectively.

Ethics - The study was approved from the Ethical Committee of the Doutor Heitor Vieira Dourado Tropical Medicine Foundation (Manaus) (CAAE: 0013.0.114.00008). An adult inhabitant of each participating household gave written informed consent to receive intervention traps and/or to participate in the serological study.

\section{RESULTS}

First questionnaire - 518 persons (66.4\% females) responded the first questionnaire. The vast majority of respondents had heard about dengue fever $(99.2 \%)$ and about the haemorrhagic form of the disease (98.6\%). More than half of participants (59.3\%) stated that at least one member of the family has already had dengue fever with $59.7 \%$ of them being diagnosed by a physician.
Seventy one percent of the sample had already heard of a fatal dengue case in Manaus. Most participants knew control measures against dengue fever and $85.9 \%$ stated to have recently applied one of such measures.

Baseline comparison between mass trapping and control arm indicated significant differences in the categories "neighbourhood solidarity", "neighbourhood familiarity" and "community awareness", in a way that participants from the intervention arm agreed more frequently with the three statements (Table II). There were no differences between the categories education, house equipment and application of dengue control measures.

Study participation - Of the 403 households in the intervention arm, 206 (51.1\%) agreed to participate in the study. Therefore, 618 MQTs were installed (3 traps per house). Participation in the three clusters varied between $47-54 \%$. The percentage of participating households increased during the study, so that after 17 months, 212 houses (53\%) were using MQTs for mass trapping. Five households asked to leave the study, however 11 houses that initially refused to participate were included later during the study.

Total mosquito collections - MQTs collected 31,941 mosquitoes, 21,023 (65.8\%) Culex spp (71.9\% females), $10,633(33.3 \%)$ Ae. aegypti (91.7\% females) and 285 ( $0.9 \%)$ Aedes albopictus (Skuse) (81.8\% females) (Table III).

Entomological monitoring - During baseline monitoring, BGS traps collected a mean number of $( \pm$ SD) $1.05( \pm 0.93)$ and $1.63( \pm 1.62)$ Ae. aegypti females in the intervention and control arm, respectively (Table IV). There was no significant difference between female $A e$. aegypti catches in the two types of areas (Table V).

Monitoring results suggest that adult female Ae. aegypti abundance was higher in the mass trapping arm during all three periods of the experiment (Fig. 2A).

TABLE II

Baseline questionnaire (comparison between intervention and control arm)

\begin{tabular}{|c|c|c|c|c|c|}
\hline \multirow[b]{2}{*}{ Variables } & \multicolumn{2}{|c|}{ Intervention } & \multicolumn{2}{|c|}{ Control } & \multirow[b]{5}{*}{$\mathrm{p}$} \\
\hline & Mean \pm SD & $\mathrm{N}$ & Mean $\pm \mathrm{SD}$ & $\mathrm{N}$ & \\
\hline Age & $41.9 \pm 13.7$ & 253 & $39.5 \pm 15.1$ & 264 & \\
\hline Persons per household & $4.7 \pm 2$ & 251 & $4.6 \pm 1.8$ & 264 & \\
\hline Binary variables & $\mathrm{n}(\%)$ & $\mathrm{n}$ & $\mathrm{n}(\%)$ & $\mathrm{n}$ & \\
\hline Education $^{a}$ & $160(63.7)$ & 251 & $176(66.7)$ & 264 & 0.85 \\
\hline Household equipment ${ }^{b}$ & $129(52.2)$ & 247 & $132(50.2)$ & 263 & 0.99 \\
\hline Application of control measures & $228(90.1)$ & 253 & $215(81.7)$ & 263 & 0.21 \\
\hline Neighbourhood solidarity ${ }^{c}$ & $197(99.5)$ & 198 & $179(86.9)$ & 206 & 0.0009 \\
\hline Neighbourhood familiarity ${ }^{d}$ & $185(96.4)$ & 192 & $161(89)$ & 181 & 0.009 \\
\hline Community awareness ${ }^{e}$ & $172(92.5)$ & 186 & $139(79.8)$ & 174 & 0.019 \\
\hline
\end{tabular}

$a$ : above primary school; $b$ : air condition; $c$ : participants were asked if they agree with the statement "people in my neighbourhood would help together to fight common problems"; $d$ : participants were asked if they agree with the statement "people in my neighbourhood know each other well"; $e$ : participants were asked if they agree with the statement "dengue fever is commonly discussed in my neighbourhood"; n: number of agreements (yes) for questions with binary variables; N: number of observations; SD: standard deviation. 
TABLE III

Sex-specific number of mosquitoes collected in MosquiTRAP intervention traps

\begin{tabular}{|c|c|c|c|c|c|c|}
\hline & \multicolumn{2}{|c|}{ Aedes aegypti } & \multicolumn{2}{|c|}{ Aedes albopictus } & \multicolumn{2}{|c|}{ Culex sp. } \\
\hline & Females & Males & Females & Males & Females & Males \\
\hline Sum & 9,747 & 886 & 233 & 52 & 15,162 & 5,861 \\
\hline Mean (2 week) & 1.4 & 0.12 & 0.03 & 0.007 & 2.13 & 0.82 \\
\hline Standard deviation & 2.1 & 0.54 & 0.23 & 0.15 & 3.27 & 2.14 \\
\hline Max (2 week) & 30 & 8 & 5 & 9 & 111 & 26 \\
\hline
\end{tabular}

all values are based on the sum of three traps that were installed in the same household.

\section{TABLE IV}

Overview of the mean number of female Aedes aegypti caught with BG-Sentinel monitoring traps in $24 \mathrm{~h}$ at the baseline period and during three different periods after beginning of mass trapping with MosquiTRAPs

\begin{tabular}{|c|c|c|c|c|c|c|c|c|}
\hline \multirow[b]{3}{*}{ Pair } & \multirow{2}{*}{\multicolumn{2}{|c|}{$\begin{array}{c}\text { Weeks -8-0 } \\
\begin{array}{c}\text { Baseline } \\
(\text { mean } \pm \mathrm{SD})\end{array}\end{array}$}} & \multirow{2}{*}{\multicolumn{2}{|c|}{$\begin{array}{c}\text { Weeks } 1-22 \\
\begin{array}{c}\text { Rainy season } 1 \\
(\text { mean } \pm \mathrm{SD})\end{array}\end{array}$}} & \multirow{2}{*}{\multicolumn{2}{|c|}{$\begin{array}{c}\text { Weeks 23-42 } \\
\begin{array}{c}\text { Dry season } \\
(\text { mean } \pm \mathrm{SD})\end{array}\end{array}$}} & \multirow{2}{*}{\multicolumn{2}{|c|}{$\begin{array}{c}\text { Weeks } 43-73 \\
\begin{array}{c}\text { Rainy season } 2 \\
(\text { mean } \pm \mathrm{SD})\end{array}\end{array}$}} \\
\hline & & & & & & & & \\
\hline & Intervention & Control & Intervention & Control & Intervention & Control & Intervention & Control \\
\hline 1 & $0.58(0.59)$ & $0.69(0.77)$ & $1.57(1.23)$ & $1.66(0.97)$ & $0.78(0.57)$ & $0.50(0.71)$ & $0.70(0.83)$ & $0.34(0.38)$ \\
\hline 2 & $1.25(0.74)$ & $1.90(2.27)$ & $1.50(1.33)$ & $0.49(0.40)$ & $0.80(0.30)$ & $0.21(0.30)$ & $0.59(0.56)$ & $0.02(0.06)$ \\
\hline 3 & $1.42(1.51)$ & $2.31(1.39)$ & $6.08(4.96)$ & $1.13(1.06)$ & $5.96(3.32)$ & $0.40(0.35)$ & $10.98(18.91)$ & $0.26(0.29)$ \\
\hline \multicolumn{9}{|l|}{ Total } \\
\hline $1-3$ & $1.05(0.93)$ & $1.63(1.62)$ & $3.05(0.74)$ & $1.09(0.96)$ & $2.51(3.13)$ & $0.37(0.49)$ & 4.09 (11.78) & $0.21(0.30)$ \\
\hline $1-2$ & $0.92(0.71)$ & $1.29(1.70)$ & $1.53(1.25)$ & $1.08(0.94)$ & $0.79(0.59)$ & $0.35(0.55)$ & $0.65(0.70)$ & $0.18(0.31)$ \\
\hline
\end{tabular}

presented are mean catch rates $( \pm$ standard deviation) per pair and treatment category for the baseline and the post-intervention periods. The total mean is presented for all three cluster pairs and for pairs 1 and 2 (not taking in consideration pair 3 , which had an exceptionally high mosquito density).

Female Ae. aegypti catch rates in the mass trapping cluster of pair 3 increased considerably after baseline monitoring, whilst the catches in the control cluster of the same pair decreased (Table IV). An analysis of the mosquito abundance time series in this cluster pointed that weekly mean numbers of Ae. aegypti females were between 8.3-38.9 times higher in comparison to the remaining five clusters. The cluster was therefore considered an outlier and additional data analysis was performed, taking into consideration only two cluster pairs.

The time series of mean female Ae. aegypti abundance which considered only two cluster pairs still revealed higher dengue vector abundance in the intervention arm during most of the study period (Fig. 2B). Fig. 3A, B shows the smooth effect of time on female Ae. aegypti abundance during the whole study period in all three cluster pairs and in the two normal pairs of clusters, respectively. Both graphs indicate a decline of mosquitoes in the control areas, representing the natural fluctuation of the mosquito population during the study period. Mosquito abundance oscillated in the mass trap- ping clusters, resulting in two peaks: one at the beginning of the first rainy season and another at the transition from the dry season to the second rainy season.

Considering all data that were collected during the mass trapping intervention (weeks 1-73) and all three pair of clusters, the GAMM controlled by Clogbaseline and by the interaction between Clogbaseline and treatment indicated a significantly higher abundance of female $A e$. aegypti in the intervention $\operatorname{arm}(\mathrm{p}=0.008)$. The mean difference between treatments was $1.15( \pm 0.33)$ Ae. aegypti per trap per day (back-transformed effect size \pm standard error) (Table V). The GAM for the same study period (considering only cluster pairs 1 and 2) also pointed a significantly higher abundance of mosquitoes in the treatment arm, however with a smaller effect size (a mean difference of $0.29 \pm 0.07$ females between treatments) (Table V). GAMs that were adjusted for the separate study periods indicated no significant difference of mosquito abundance between treatment arms during the first rainy season $(\mathrm{p}=0.141$, effect size $=0.20 \pm 0.13)$ and significantly higher abundance of female Ae. aegypti in the treatment 
TABLE V

Overview of the models used per time period to analyse variation in $\log _{10}$-transformed mean number of Aedes aegypti females caught with BG-Sentinel monitoring traps

\begin{tabular}{|c|c|c|c|c|c|c|}
\hline Pairs & Period & Model & Variable & Effect & SE & $\mathrm{p}$ \\
\hline $1-3$ & $\begin{array}{c}\text { All data } \\
\text { (weeks -8-73) }\end{array}$ & $\mathrm{Y}_{h i}=\alpha+\mathrm{f}_{T h}(i)+\mathrm{a}_{h}+\varepsilon_{h i}$ & $\begin{array}{l}\text { treatment } \mid \text { week } \\
\text { control } \mid \text { week }\end{array}$ & $\begin{array}{l}\text { Smooth } \\
\text { Smooth }\end{array}$ & $\begin{array}{l}- \\
-\end{array}$ & $\begin{array}{l}<0.001 \\
<0.001\end{array}$ \\
\hline $1-3$ & $\begin{array}{c}\text { Baseline } \\
\text { (weeks -8-0) }\end{array}$ & $\mathrm{Y}_{h i}=\alpha+\beta T_{h}+\mathrm{a}_{h}+\varepsilon_{h i}$ & treatment & -0.189 & 0.235 & 0.466 \\
\hline $1-3$ & $\begin{array}{l}\text { Intervention } \\
\text { (weeks 1-73) }\end{array}$ & $\mathrm{Y}_{h I}=\alpha+\beta_{1} \cdot T_{h}+\beta_{2} \cdot P_{h}+\beta_{3} \cdot T_{h} \cdot P_{h+} \mathrm{f}_{T h}(i)+\mathrm{a}_{h}+\varepsilon_{h i}$ & $\begin{array}{c}\text { treatment } \\
\text { Clogbaseline }^{a} \\
\text { treatment:Clogbaseline } \\
\text { treatment|week } \\
\text { control|week }\end{array}$ & $\begin{array}{c}0.766 \\
-0.276 \\
2.046 \\
\text { Smooth } \\
\text { Smooth }\end{array}$ & $\begin{array}{c}0.288 \\
0.616 \\
1.169 \\
- \\
-\end{array}$ & $\begin{array}{c}0.008 \\
0.655 \\
0.082 \\
<0.001 \\
<0.001\end{array}$ \\
\hline $1-2$ & $\begin{array}{c}\text { All data } \\
\text { (weeks -8-73) }\end{array}$ & $\mathrm{Y}_{h i}=\alpha+\mathrm{f}_{T h}(i)+\varepsilon_{h i}$ & $\begin{array}{l}\text { treatment } \mid \text { week } \\
\text { control|week }\end{array}$ & $\begin{array}{l}\text { Smooth } \\
\text { Smooth }\end{array}$ & $\begin{array}{l}- \\
-\end{array}$ & $\begin{array}{l}<0.001 \\
<0.01\end{array}$ \\
\hline $1-2$ & $\begin{array}{c}\text { Baseline } \\
\text { (weeks -8-0) }\end{array}$ & $\mathrm{Y}_{h i}=\alpha+\beta T_{h}+\varepsilon_{h i}$ & treatment & -0.076 & 0.276 & 0.81 \\
\hline $1-2$ & $\begin{array}{l}\text { Intervention } \\
\text { (weeks 1-73) }\end{array}$ & $\mathrm{Y}_{h i}=\alpha+\beta_{1} \cdot T_{h}+\beta_{2} \cdot P_{h}+\beta_{3} \cdot T_{h} \cdot P_{h+} \mathrm{f}_{T h}(i)+\varepsilon_{h i}$ & $\begin{array}{c}\text { treatment } \\
\text { Clogbaseline } \\
\text { treatment:Clogbaseline } \\
\text { treatment|week } \\
\text { control|week }\end{array}$ & $\begin{array}{c}0.257 \\
-0.58 \\
0.513 \\
\text { Smooth } \\
\text { Smooth }\end{array}$ & $\begin{array}{l}0.065 \\
0.123 \\
0.265 \\
- \\
-\end{array}$ & $\begin{array}{l}<0.001 \\
<0.001 \\
<0.001 \\
<0.001 \\
<0.001\end{array}$ \\
\hline
\end{tabular}

a: the $\log _{10}$-transformed and centred mean number of Ae. aegypti females caught during baseline monitoring; SE: standard error.

A

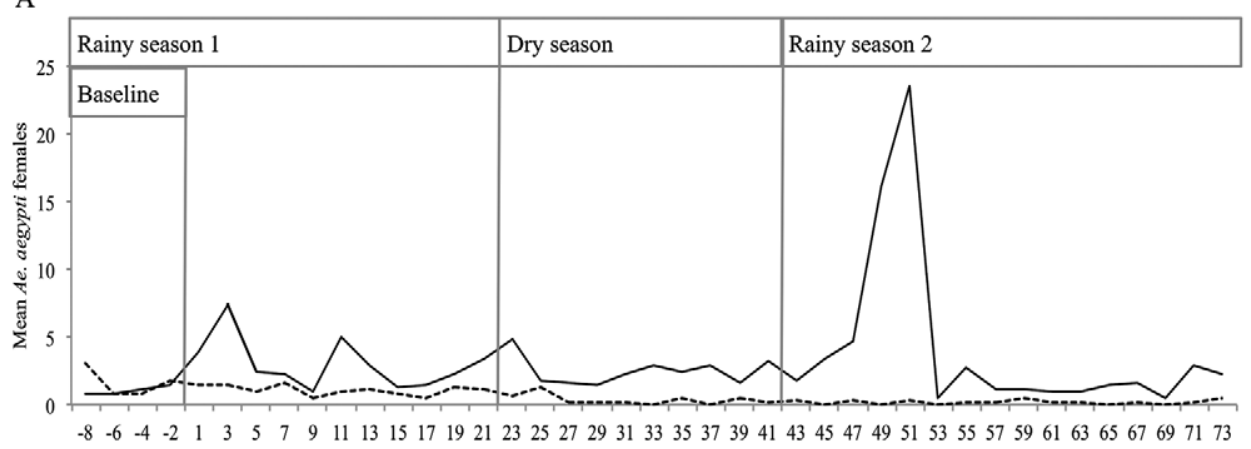

B

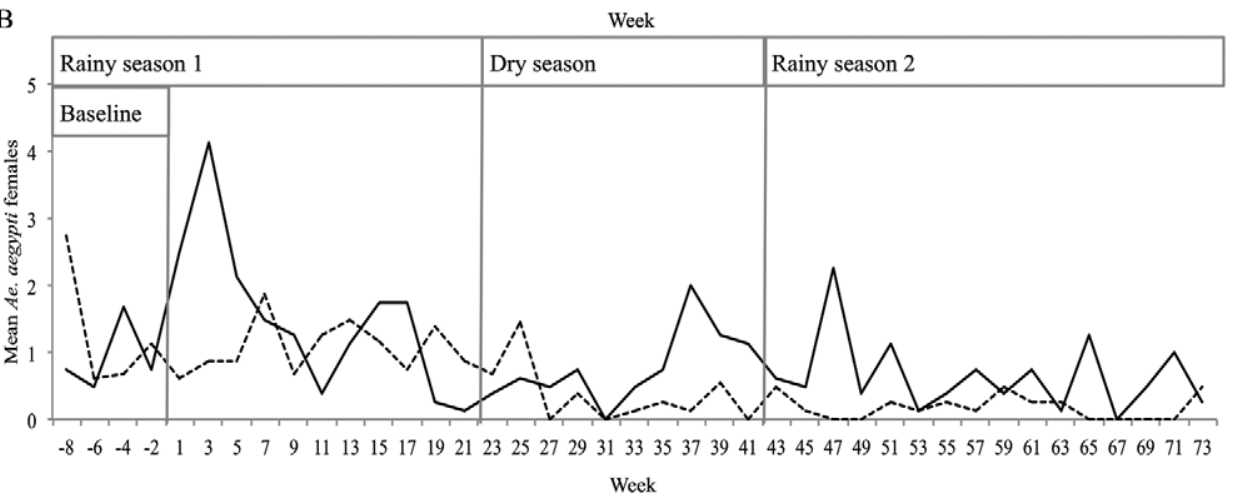

Fig. 2: monitoring with BG-Sentinel traps: mean number of adult female Aedes aegypti caught in the MosquiTRAP mass trapping arm (solid line) and the control arm (dotted line). A: mean of all three cluster pairs; B: mean of cluster pairs 1 and 2. Note the scale difference of the y-axis between A and B. 

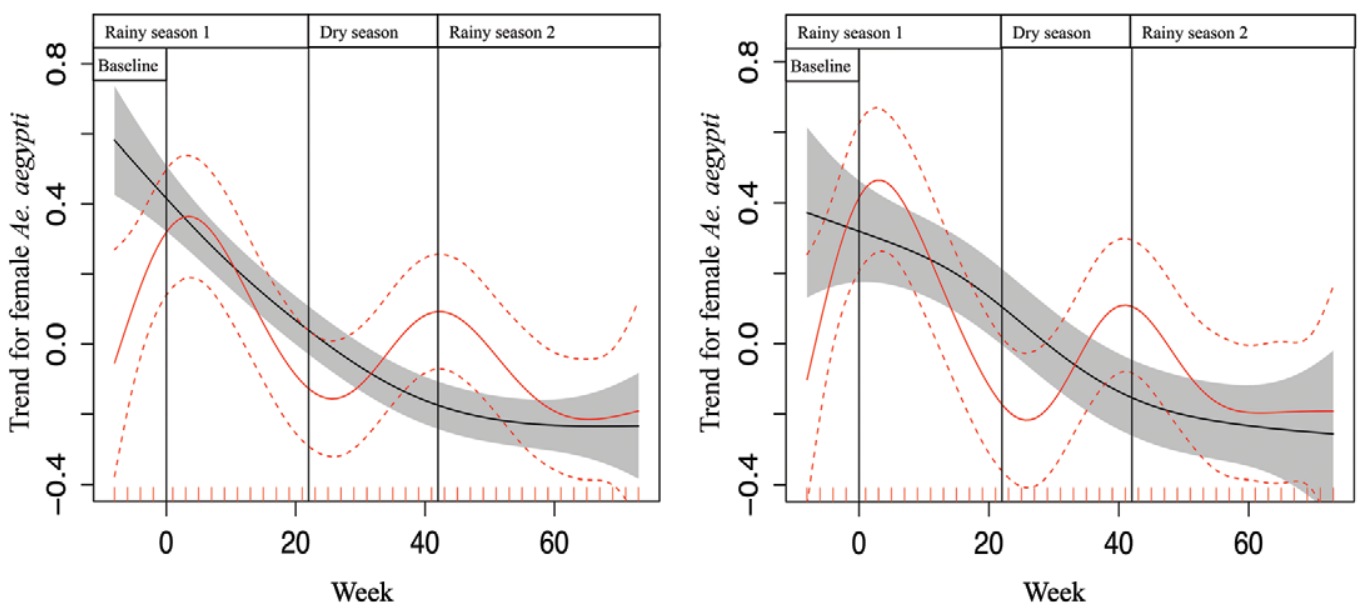

Fig. 3: estimated trends for log-transformed Aedes aegypti females collected in BG-Sentinel monitoring traps. A: according to the generalised additive mixed model 1 for all three cluster pairs; B: according to the generalised additive model for cluster pairs 1 and 2; black line: control arm; red line: MosquiTRAP mass trapping arm. The shadowed areas and red dashed lines indicate the $95 \%$ confidence interval for control and MosquiTRAP mass trapping clusters, respectively. Note that the baseline period (weeks -8-0) is included.

TABLE VI

Physiological status of female Aedes aegypti caught in BG-Sentinel monitoring traps

\begin{tabular}{|c|c|c|c|c|c|c|c|c|}
\hline \multirow[b]{3}{*}{ Period } & \multicolumn{4}{|c|}{ Intervention } & \multicolumn{4}{|c|}{ Control } \\
\hline & \multicolumn{3}{|c|}{$\begin{array}{c}\text { Physiological status } \\
\mathrm{n}(\%)\end{array}$} & \multirow{2}{*}{$\begin{array}{c}\text { Parous rate } \\
\quad(\%)\end{array}$} & \multicolumn{3}{|c|}{$\begin{array}{c}\text { Physiological status } \\
\mathrm{n}(\%)\end{array}$} & \multirow{2}{*}{$\begin{array}{c}\text { Parous rate } \\
\text { (\%) }\end{array}$} \\
\hline & Nulliparous & Parous & Late stages & & Nulliparous & Parous & Late stages & \\
\hline \multicolumn{9}{|l|}{ Pairs 1-3 } \\
\hline Baseline & $5(12.2)$ & $11(26.8)$ & $25(61)$ & 68.8 & $4(5.7)$ & $25(35.7)$ & $41(58.6)$ & 86.2 \\
\hline Weeks 1-22 & $18(4.8)$ & 94 (24.9) & $265(70.3)$ & 83.9 & $4(3.1)$ & $47(36.4)$ & $78(60.5)$ & 92.2 \\
\hline Weeks 23-42 & $0(0)$ & $85(40.3)$ & $126(59.7)$ & 100 & $0(0)$ & $13(40.6)$ & $19(59.4)$ & 100 \\
\hline Weeks 43-73 & $49(5.9)$ & $107(12.8)$ & $681(81.4)$ & 68.6 & $1(2.2)$ & $9(19.6)$ & $36(78.3)$ & 90 \\
\hline \multicolumn{9}{|l|}{ Pairs 1-2 } \\
\hline Baseline & $5(20.8)$ & $6(25)$ & $13(54.2)$ & 54.5 & $1(2.8)$ & $13(36.1)$ & $22(61.1)$ & 92.9 \\
\hline Weeks 1-22 & $3(2.3)$ & $34(25.8)$ & 95 (71.9) & 91.9 & $2(2.4)$ & $32(37.6)$ & $51(60)$ & 94.1 \\
\hline Weeks 23-42 & $0(0)$ & $16(34.8)$ & $30(65.2)$ & 100 & $0(0)$ & $10(43.5)$ & $13(56.5)$ & 100 \\
\hline Weeks 43-73 & $2(2)$ & $10(10)$ & $88(88)$ & 83.3 & $1(3.7)$ & $4(14.8)$ & $22(81.5)$ & 80 \\
\hline
\end{tabular}

presented are for the baseline and three intervention periods, the number and percentage (bracketed) of female mosquitoes in intervention and control arm that were nulliparous, parous or in late ovarian development stages and the parous rate (i.e., the fraction of nulliparous and parous females being parous). Please note that, as the mosquito infestation in one cluster was exceptionally high, data is presented for all three cluster pairs and for two cluster pairs.

arm during the dry season $(\mathrm{p}=0.01$; back-transformed effect size $=0.34 \pm 0.11)$ and second rainy season $(\mathrm{p}=$ 0.003 , back-transformed effect size $=0.33 \pm 0.086$ ).

Parity - Dissections were performed on 1,630 (91.1\%) from 1,789 Ae. aegypti females that were collected in BGS monitoring traps. Predominantly females in advanced stages of ovarian development were collected in both intervention and control clusters in all study periods (Table VI).
Frequencies of parous and nulliparous females were similar in intervention and control arm in all study periods for the whole dataset ( 3 cluster pairs) and for the reduced dataset ( 2 cluster pairs) $(\mathrm{p}>0.05)$.

Serological survey - DENV IgM positive samples were rare in the study area (Table VII). The frequency of DENV IgM seropositivity was similar between treated houses in the intervention arm and the control arm when 


\section{TABLE VII}

Results of the dengue virus (DENV) IgM seropositivity survey in the intervention and control arm

\begin{tabular}{lcccc}
\hline Area & House type & $\begin{array}{c}\text { Negative } \\
(\mathrm{n})\end{array}$ & $\begin{array}{c}\text { Positive } \\
(\mathrm{n})\end{array}$ & $\begin{array}{c}\text { Positive } \\
(\%)\end{array}$ \\
\hline Pairs 1-3 & & & & \\
$\quad$ Intervention & With trap & 174 & 2 & 1.1 \\
Intervention & Without trap & 15 & 0 & 0 \\
Control & - & 148 & 1 & 0.7 \\
Pairs 1-2 & & & & \\
Intervention & With trap & 127 & 1 & 0.8 \\
Intervention & Without trap & 10 & 0 & 0 \\
Control & - & 117 & 1 & 0.8 \\
\hline
\end{tabular}

presented are the frequencies of samples that were found seronegative and seropositive for DENV IgM. As the mosquito infestation in one cluster was exceptionally high, data is presented for all three cluster pairs and for two cluster pairs. Note that in intervention clusters, blood samples were obtained from residents of participating ("with trap") and nonparticipating ("without trap") households.

considering the whole dataset [Fisher's exact test, $\mathrm{p}=1$; odds ratio $(\mathrm{OR})=0.59$ ] and when the outlier cluster pair was not considered (Fisher's exact test, $\mathrm{p}=1 ; \mathrm{OR}=1.08$ ), suggesting that trap usage did not affect seropositivity.

Second questionnaire - Most participants of the second questionnaire stated that the MQTs notably reduced the mosquito density (86.4\%) and annoyance (86.9\%) in their homes. Seventy percent of participants stated to be less worried about dengue fever and $40.8 \%$ felt more protected against the disease when using the trap. The majority of participants $(89.6 \%)$ stated to be content with the trap and $95.3 \%$ agreed that the traps were comfortable to use. Of the five householders who reported inconveniences of trap usage, one specified that the health agents' fortnightly trap inspections bothered. The remaining four trap users did not specify the perceived discomfort.

\section{DISCUSSION}

Entomological monitoring indicated that MQT mass trapping using three traps per premise in about $50 \%$ of all premises did not reduce the abundance of adult dengue vectors. On the contrary, during the intervention period, BGS monitoring traps in the intervention arm collected significantly more female Ae. aegypti mosquitoes than in the control arm, even when the outlier cluster pair was excluded from the analysis.

The gravid mosquitoes that are trapped on a MQTs' sticky card can lay eggs, which may fall directly in the trap's water. The development of larvae in MQTs is therefore possible and has been previously described (Maciel-de-Freitas et al. 2008). The patronised use of MQTs for monitoring purposes consists in weekly trap inspections, during which the water in the inferior part of the traps is substituted. In this way, the time for completion of the development from immature forms to adults is insufficient. Theoretically, as intervals between trap inspections were two weeks in the present study, complete development might have occurred. To eliminate this possibility, a drop of $B t i$ was added to the water in MQTs during fortnightly trap inspections.

Santos et al. (2003), who simultaneously offered ovitraps with tap water and ovitraps with tap water and $B t i$ to gravid $A e$. aegypti, found that the larvicide did not interfere significantly with the mosquitoes' trap choice. We therefore expect that the addition of Bti neither increased nor reduced the catches of MQTs. The larvicidal action of the $B t i$ was confirmed in a complementary experiment in which 50 larvae (L3/L4) were added to MQTs 30, 45 and 60 days after having added one drop of Bti to the traps' water. The mortality rates in the three treatments were $100 \%, 97.3 \%$ and $42.1 \%$ (PB Trindade and CL Gonçalves, unpublished observations). It is therefore unlikely that the MQTs have turned into breeding sites, even if health agents occasionally forgot to add Bti to the traps. It is more probable that the number of breeding sites increased in the treatment arm. However, this factor was not monitored.

The MQT could be improved in a way which makes it impossible to turn into a breeding site without the use of Bti. A mosquito net might be positioned inside the MQT, right above the water surface. In this way, eventually developing adults would not be able to emerge from the trap.

The results of a questionnaire applied to Brazilians suggested that people would relax their vector control practices in the presence of a dengue vaccine (Boccia et al. 2014). It might therefore have happened that participating households in the treatment arm reduced mosquito control activities, thinking that the three traps will kill all mosquitoes, making environmental control measures unnecessary. This suspicion is reinforced by the result of the second questionnaire, that $70 \%$ of participants were less concerned about dengue since the installation of the MQTs. It was however not investigated, if inhabitants applied less dengue control measures after the installation of the traps. The potential change of mosquito control behaviour should be investigated in future studies.

The mean catch rate of all three MQTs that were installed per household was 0.1 female Ae. aegypti per day. In the mass trapping experiment with BGS traps, at least 0.26 female Ae. aegypti were trapped per house. Actual BGS catches were probably much higher, considering the loss of trapped mosquitoes because of ants and power failures (Degener et al. 2014). One BGS intervention trap therefore collected at least 2.6 times more female Ae. aegypti than three MQTs. The BGS treatment resulted in a significant reduction of the female Ae. aegypti population during the first rainy month of the study. In order to obtain a comparable mosquito catch rate with MQTs, at least eight traps would have been necessary to be installed per house.

Perich et al. (2003) conducted a mass deployment study of LOs against dengue vectors in Brazil and reported a significant treatment effect. A similar work from Thailand found a significant effect of the LO intervention in one of two study years (Sithiprasasna et al. 2003). In these two studies, $100 \%$ of the houses in the intervention areas received 10 LOs. Additionally, all the houses 
in neighbouring blocks were treated in the same way to create buffer zones (aiming to minimise mosquito migration). The use of 10 traps per house however appears to be impracticable, as (i) it is unlikely that all households have 10 appropriate installation sites for the traps, which may be maintained for long time periods, (ii) the high number of traps increases considerably the time spent during trap inspections or make it unlikely, that householders will properly maintain the traps if there is no support given by local health agents and (iii) increased costs. In our study, only $50 \%$ of the houses in the study area participated, the number of traps per house was much smaller and there were no buffer zones around treatment clusters.

The use of sticky ovitraps (CDC-AGO traps) decreased the Ae. aegypti population by $60-88 \%$ in intervention areas when compared to untreated controls in Puerto Rico (Barrera et al. 2014a, b). As in our experiment, households in Puerto Rico received three sticky traps. The main difference is that the studies from Barrera et al. $(2014 \mathrm{a}, \mathrm{b})$ were executed in isolated urban areas, whilst our study was performed in six areas that are located in the middle of an extensive urban neighbourhood, favouring mosquito migration from adjacent nontreated blocks. Furthermore, more households (81-85\%) participated in Puerto Rico in comparison to our study (51\%). These factors have probably contributed to our opposing results and should be taken into consideration for future mass trapping experiments.

Absence of an effect of LO treatment was observed before in Colombia, where three different treatments were compared to a control, where only an educational campaign was implemented. The authors observed insignificant differences between Ae. aegypti abundance in areas of the four treatment types (Ocampo et al. 2009).

Frequencies of parous and nulliparous dengue vectors were similar in intervention and treatment arm in all three study periods. The age structure of the local Ae. aegypti population was therefore unaffected by MQT mass trapping. This agrees with results from an Australian study that evaluated LO mass deployment in association with larval control (Rapley et al. 2009). In contrast, we observed a significant difference between parity in intervention and control arm during the first rainy season of a BGS mass trapping experiment. This was also the only study period in which we observed a significant treatment effect on female Ae. aegypti abundance (Degener et al. 2014).

The frequency of DENV IgM seropositivity was also not affected by the mass trapping treatment. A limitation of the study was that DENV seroprevalence was not evaluated at baseline and that mosquito infection rates were not investigated. Furthermore, people from the control arm were less motivated to participate in the serological study. For this reason, we collected 149 blood samples from the control arm and 191 from the intervention arm.

The answers of the first questionnaire revealed that the vast majority of the study area's inhabitants were informed about dengue fever and dengue haemorrhagic fever and about $60 \%$ of the families were already affected by dengue. People were aware of the dengue risk and well informed about preventive measures, which were applied by most families few days before the interview survey. The percentage of respondents that replied to recently have applied such control measures was higher in the intervention arm, however without significant difference to the control arm. "Education" and "household equipment" variables that reflect the socioeconomic status of families did not differ significantly between arms. Respondents in the mass trapping arm agreed significantly more often to the affirmations of "neighbourhood solidarity", "neighbourhood familiarity" and "community awareness". It is not clear if these differences affected in some way the results of the study or the willingness of inhabitants to participate.

The majority of participants that responded the second questionnaire $(>86 \%)$ stated to have perceived a reduction of mosquito abundance and annoyance, despite the fact that the monitoring results in the intervention arm did not suggest a diminishing trend of dengue vector abundance during the study period. In the BGS mass trapping experiment, a similar percentage of participants (89\%) affirmed that mass trapping reduced the abundance of mosquitoes (Degener et al. 2014). In this case, we attributed the perceived effect to the high Culex catch rates of BGS traps (mean catch rate: at least 31.8 females per trap per 2 weeks) (Degener et al. 2014). In the present study, the three MQTs that were installed in each household collected a mean number of 2.3 female Culex per day, about 14 times less than BGS intervention traps. It is therefore likely that the perceived effect of reduced mosquito abundance was a placebo effect. It is also possible that study participants responded in a way that they expected as being viewed as favourable by the field workers who performed the interview, biasing results towards overestimation of the traps' effect on mosquito abundance.

The vast majority of participants stated to have noticed a positive effect of MQT mass trapping on mosquito abundance, but only $41 \%$ stated to feel more protected against dengue fever. This discrepancy might reflect some skepticism about the MQTs' capacity to reduce the DENV infection risk. In the BGS mass trapping experiment, we also observed a discrepancy between the perceived effect on mosquito abundance and the percentage of participants that felt more protected against dengue fever. However, a higher percentage of BGS trap users $(61 \%)$ felt more protected against dengue (Degener et al. 2014), suggesting that BGS traps were believed to be more efficient than MQT for catching mosquitoes and hence to protect people from DENV infections.

At the beginning of the present study, $51.1 \%$ of the households in the intervention arm participated and, during the 17 months of mass trapping, this number increased to $53 \%$, reflecting that trap users were undisturbed by the presence of three MQTs in the peridomestic area of their houses. In the BGS mass trapping experiment, the percentage of participating households decreased from $60.5-36 \%$, probably because of trap users' worry of increased energy costs and fear of the trap to catch fire (Degener et al. 2014). Studies of LO mass deployment in Brazil, Thailand and Australia and of sticky ovitrap mass trapping in Puerto Rico reported the participation of $71-100 \%$ of households (Perich et al. 2003, Sithiprasasna et al. 2003, Rapley et al. 2009, Bar- 
rera et al. 2014a). Therefore, we obtained a low participation rate in comparison to other studies. An investigation from the state of São Paulo, Brazil, identified aspects that interfere with the local population's adherence to routinely applied dengue control programs. The authors identified householders' refusal as the principal problem in different neighbourhoods with distinct socioeconomic classes (Chiaravalloti-Neto et al. 2007).

In the present study, which is the first evaluation of Ae. aegypti mass trapping using MQTs, the intervention did not have a reducing effect on dengue vector abundance. Opposing our results, several similar studies that used LOs instead of sticky traps, described a significant effect on entomological indicators, at least during some period of the investigations (Perich et al. 2003, Sithiprasasna et al. 2003, Rapley et al. 2009). Furthermore, the efficiency of the sticky CDC-AGO traps was shown in Puerto Rico (Barrera et al. 2014a, b). The absence of an effect in our study might be associated with various factor such as: (i) lack of buffer zones and consequently migration of mosquitoes from neighbouring nontreated areas, (ii) small size of clusters, (iii) insufficient collection efficacy of the trap or insufficient quantity of traps per household, (iv) increasing mosquito population in the treatment arm after baseline monitoring and (v) low participation. Additionally, the study was performed during a time of low dengue transmission, which made it impossible to detect a possible effect of mass trapping on DENV infection rates. The low number of clusters ( 3 clusters per treatment arm) was also a limiting factor.

Even if MQTs did not positively affect dengue vector infestation, parity rates and IgM seropositivity, some favourable aspects could be identified. The fact that during the study period of 17 months only five households requested to have their MQTs removed reflects good acceptance of the traps and of fortnightly trap inspections - fundamental factors for the application of mass trapping in large scale. The installation of MQTs is relatively easy, as they don't require electricity. In mass deployment studies with LOs, quantification of mosquitoes being killed by intervention traps is impossible. Using sticky traps on the other hand makes mosquito quantification and identification fast, easy and cheap because no laboratory is needed. The use of the sticky card for trapping mosquitoes eliminates the problem of reduced trap efficiency due to fungal contamination, a phenomenon that was previously observed on insecticide-impregnated oviposition strips in LOs (Sithiprasasna et al. 2003). The development of resistance against insecticides used is another disadvantage of LOs (Ocampo et al. 2009), which does not apply to sticky traps. The use of the MQTs however should be limited to Ae. aegypti monitoring.

\section{ACKNOWLEDGEMENTS}

To all inhabitants of Cidade Nova who participated in the study, to Luzia Mustáfa, Ricardo Passos, Wanderson Sampaio and all field workers from the Foundation of Health Vigilance, to the Virology Department of the FMT-HVD, under supervision of Maria Paula Gomes Mourão, for the collection of blood samples, and to the Entomology Department of the FMTHVD, under supervision of Maria das Graças Vale Barbosa and Nelson Ferreira Fé, for assistance in processing the catch bags that returned from the field.

\section{REFERENCES}

Barrera R, Amador M, Acevedo V, Caban B, Felix G, Mackay AJ 2014a. Use of the CDC autocidal gravid ovitrap to control and prevent outbreaks of Aedes aegypti (Diptera: Culicidae). J Med Entomol 51: 145-154.

Barrera R, Amador M, Acevedo V, Hemme RR, Felix G 2014b. Sustained, area-wide control of Aedes aegypti using CDC autocidal gravid ovitraps. Am J Trop Med Hyg 91: 1269-1276.

Bates D, Maechler M, Bolker B 2011. 1me4: linear mixed effects models using S4 classes. R package version 0.999375-39. Available from: cran.r-project.org/web/packages/lme4/index.html.

Boccia TMQR, Burattini MN, Coutinho FAB, Massad E 2014. Will people change their vector-control practices in the presence of an imperfect dengue vaccine? Epidemiol Infect 142: 625-633.

Chan KL 1972. The eradication of Aedes aegypti at the Singapore Paya Lebar International Airport. Proceedings of the Vector Control in Southeast Asia, 1st Southeast Asian Ministers of Education Organization-Tropical Medicine Vector Control Workshop, 1972 August 17-18, Singapore, Sen Wah Press, Singapore, p. 85-88.

Chiaravalloti-Neto F, Baglini V, Cesarino MB, Fávaro EA, Mondini A, Ferreira AC, Dibo MR, Barbosa AA, Ferraz AA 2007. Programa de controle da dengue em São José do Rio Preto, São Paulo, Brasil: dificuldades para a atuação dos agentes e adesão da população. Cad Saude Publica 23: 1656-1664.

Degener CM, Eiras AE, Ázara TMF, Roque RA, Rösner S, Codeço CT, Nobre AA, Rocha ESO, Kroon EG, Ohly JJ, Geier M 2014. Evaluation of the effectiveness of mass trapping with BG-sentinel traps for dengue vector control: a cluster randomized controlled trial in Manaus, Brazil. J Med Entomol 51: 408-420.

Eiras AE, Resende MC 2009. Preliminary evaluation of the 'DengueMI' technology for Aedes aegypti monitoring and control. Cad Saude Publica 25 (Suppl. 1): 45-58.

Fávaro EA, Dibo MR, Mondini A, Ferreira AC, Barbosa AA, Eiras AE, Barata EA, Chiaravalloti-Neto F 2006. Physiological state of Aedes (Stegomyia) aegypti mosquitoes captured with MosquiTRAPs in Mirassol, São Paulo, Brazil. J Vector Ecol 31: 285-291.

Fay RW, Eliason DA 1966. A preferred oviposition site as a surveillance method for Aedes aegypti. Mosq News 26: 531-535.

Gubler DJ 2011. Dengue, urbanization and globalization: the unholy trinity of the $21^{\text {st }}$ century. Trop Med Health 39: 3-11.

Hoffmann AA, Montgomery BL, Popovici J, Iturbe-Ormaetxe I, Johnson PH, Muzzi F, Greenfield M, Durkan M, Leong YS, Dong Y, Cook H, Axford J, Callahan AG, Kenny N, Omodei C, McGraw EA, Ryan PA, Ritchie SA, Turelli M, O’Neill SL 2011. Successful establishment of Wolbachia in Aedes populations to suppress dengue transmission. Nature 476: 454-457.

IBGE - Instituto Brasileiro de Geografia e Estatística. Censo 2010. Informações sobre bairros segundo os municípios. Available from: ibge. gov.br/home/presidencia/noticias/imprensa/ppts/0000000488.xls.

Kay B, Vu SN 2005. New strategy against Aedes aegypti in Vietnam. Lancet 365: 613-617.

Kittayapong P, Yoksan S, Chansang U, Chansang C, Bhumiratana A 2008. Suppression of dengue transmission by application of integrated vector control strategies at seropositive GIS-based foci. Am J Trop Med Hyg 78: 70-76.

Kroeger A, Lenhart A, Ochoa M, Villegas E, Levy M, Alexander N, McCall PJ 2006. Effective control of dengue vectors with curtains and water container covers treated with insecticide in Mexico and Venezuela: cluster randomised trials. BMJ 332: 1247-1252.

Lacroix R, McKemey AR, Raduan N, Wee LK, Ming WH, Ney TG, Rahidah AAS, Salman S, Subramaniam S, Nordin O, Hanum ATN, 
Angamuthu C, Mansor SM, Lees RS, Naish N, Scaife S, Gray P, Labbe G, Beech C, Nimmo D, Alphey L, Vasan SS, Lim LH, Wasi AN, Murad S 2012. Open field release of genetically engineered sterile male Aedes aegypti in Malaysia. PLoS ONE 7: e42771.

Lenhart A, Trongtokit Y, Alexander N, Apiwathnasorn C, Satimai W, Vanlerberghe V, Van der Stuyft P, McCall PJ 2013. A clusterrandomized trial of insecticide-treated curtains for dengue vector control in Thailand. Am J Trop Med Hyg 88: 254-259.

Maciel-de-Freitas R, Aguiar R, Bruno RV, Guimarães MC, Lourençode-Oliveira R, Sorgine MHF, Struchiner CJ, Valle D, O'Neill SL, Moreira LA 2012. Why do we need alternative tools to control mosquito-borne diseases in Latin America? Mem Inst Oswaldo Cruz 107: 828-829.

Maciel-de-Freitas R, Peres RC, Alves F, Brandolini MB 2008. Mosquito traps designed to capture Aedes aegypti (Diptera: Culicidae) females: preliminary comparison of Adultrap, MosquiTRAP and backpack aspirator efficiency in a dengue-endemic area of Brazil. Mem Inst Oswaldo Cruz 103: 602-605.

Mackay AJ, Amador M, Barrera R 2013. An improved autocidal gravid ovitrap for the control and surveillance of Aedes aegypti. Parasit Vectors 6: 225.

Nam VS, Yen NT, Duc HM, Tu TC, Thang VT, Le NH, San LH, Loan LL, Huong VT, Khanh LH, Trang HT, Lam LZ, Kutcher SC, Aaskov JG, Jeffery JA, Ryan PA, Kay BH 2012. Communitybased control of Aedes aegypti by using mesocyclops in southern Vietnam. Am J Trop Med Hyg 86: 850-859.

Ocampo CB, Gonzalez C, Morales CA, Perez M, Wesson D, Apperson CS 2009. Evaluation of community-based strategies for Aedes aegypti control inside houses. Biomedica 29: 282-297.

Pepin KM, Marques-Toledo C, Scherer L, Morais MM, Ellis B, Eiras AE 2013. Cost-effectiveness of novel system of mosquito surveillance and control, Brazil. Emerg Infect Dis 19: 542-550.
Perich MJ, Kardec A, Braga IA, Portal IF, Burge R, Zeichner BC, Brogdon WA, Wirtz RA 2003. Field evaluation of a lethal ovitrap against dengue vectors in Brazil. Med Vet Entomol 17: 205-210.

Pinheiro J, Bates D, DebRoy S, Sarkar D, R Development Core Team 2010. nlme: linear and nonlinear mixed effects models. R package version 3.1-97. R Development Core Team, Vienna, Austria.

R Development Core Team 2010. R: A language and environment for statistical computing. Available from: cran.r-project.org/web/ packages/lme4/index.html.

Rapley LP, Johnson PH, Williams CR, Silcock RM, Larkman M, Long SA, Russell RC, Ritchie SA 2009. A lethal ovitrap-based mass trapping scheme for dengue control in Australia. II. Impact on populations of the mosquito Aedes aegypti. Med Vet Entomol 23: 303-316.

Ritchie SA, Long S, Hart A, Webb CE, Russell RC 2003. An adulticidal sticky ovitrap for sampling container-breeding mosquitoes. J Am Mosq Control Assoc 19: 235-242.

Santos SRA, Melo-Santos MAV, Regis L 2003. Field evaluation of ovitraps consociated with grass infusion and Bacillus thuringiensis var. israelensis to determine oviposition rates of Aedes aegypti. Dengue Bull 27: 156-162.

Sithiprasasna R, Mahapibul P, Noigamol C, Perich MJ, Zeichner BC, Burge B, Norris SL, Jones JW, Schleich SS, Coleman RE 2003. Field evaluation of a lethal ovitrap for the control of Aedes aegypti (Diptera: Culicidae) in Thailand. J Med Entomol 40: 455-462.

Vilela AP, Figueiredo LB, Santos JR, Eiras AE, Bonjardim CA, Ferreira PC, Kroon EG 2010. Dengue virus 3 genotype I in Aedes aegypti mosquitoes and eggs, Brazil, 2005-2006. Emerg Infect Dis 16: 989-992.

Wood S 2006. Generalized additive models: an introduction with $R$, Chapman and Hall/CRC, Boca Raton, 384 pp.

Zeichner BC, Perich MJ 1999. Laboratory testing of a lethal ovitrap for Aedes aegypti. Med Vet Entomol 13: 234-238. 